\title{
Spatial and temporal overlaps of top predators: Dhole, tiger and leopard, and their potential preys in Huai Kha Khaeng Wildlife Sanctuary, Thailand
}

\author{
KHWANRUTAI CHARASPET, RONGLARP SUKMASUANG", NORASET KHOEWSREE, \\ MANANYA PLA-ARD, PAANWARIS PAANSRI, BOONYATIPORN KEAWDEE, YUWALUK CHANACHAI, \\ NARIS BHUMPAKPHAN \\ Department of Forest Biology, Faculty of Forestry, Kasetsart University. 10900 Bangkok, Thailand. Tel.: +66-257-90176, Fax.: +66-294-28107, \\ vemail: mronglarp@gmail.com
}

Manuscript received: 6 December 2020. Revision accepted: 8 January 2021.

\begin{abstract}
Charaspet K, Sukmasuang R, Khoewsree N, Pla-Ard M, Paansri P, Keawdee B, Chanachai Y, Bhumpakphan N. 2021. Spatial and temporal overlaps of top predators: Dhole, tiger and leopard, and their potential prey in Huai Kha Khaeng Wildlife Sanctuary, Thailand. Biodiversitas 22: 580-592. The study of the spatial-temporal overlap of top predators and their prey is important to understand competition among predators and predator-prey relationships so that the viable populations of predators and other animals can be sustained. This research aimed to study the abundance of three top predators: Dhole (Cuon alpinus), tiger (Panthera tigris) and leopard (Panthera pardus), and their potential wild prey in Huai Kha Khaeng Wildlife Sanctuary, Thailand, and to investigate the spatialtemporal overlap between those three predators, and their potential wild prey. We tested two significant hypotheses: (i) tiger and leopard had the highest spatial-temporal overlap and the spatial overlap of dhole and leopard was higher in comparison to dhole and tiger due to a higher prey overlap; (ii) the three species of large carnivore avoided spatial-temporal overlap even if they were in the same area. The study was conducted using camera traps. In addition, the spatial-temporal overlap of large carnivores and their potential prey was studied to understand the important species of prey of these large carnivores. The results showed that the spatial overlap of tiger and leopard was the highest. Dhole had significant spatial overlap with leopard, which was higher in comparison to dhole and tiger. A significant temporal overlap of dhole and leopard was not found. Also, a significant temporal overlap of tiger and leopard was not found. The results were based on hypotheses that conformed to the niche overlap index of the potential prey and the temporal overlap coefficient. There were ten important species of potential prey of large carnivores: Sambar deer (Rusa unicolor), red muntjac (Muntiacus muntjak), gaur (Bos gaurus), banteng (Bos javanicus), wild boar (Sus scrofa), Malayan porcupine (Hystrix brachyura), large Indian civet (Viverra zibetha), Asiatic black bear (Ursus thibetanus), pig-tailed macaque (Macaca nemestrina) and red jungle fowl (Gallus gallus). The important recommendation is the protection of the sanctuary from wildfires which spread from the outside in, especially in dry evergreen forest. Food resources of herbivores in the area must be managed, as well as the prevention of epidemics from livestock to wild animals.
\end{abstract}

Keywords: Spatio-temporal correlations, Thung Yai-Huai Kha Khaeng, large carnivorous mammals

\section{INTRODUCTION}

The spatial-temporal overlap between large carnivores and other wild animals in ecosystems is complicated (Rafiq et al. 2020). It is an important matter in understanding social diversity regarding competition among predators and predator-prey relationships so that the viable populations of predators and other animals can be sustained (Zhou et al 2020). The coexistence of large carnivores in an ecosystem according to the spatial-temporal overlap and niche overlap of different species of prey depends on the reaction towards each other (Pereira et al. 2012). The complex environment also defines the ecology of population both wild carnivores and wild preys (Qi et al. 2020), and the dynamics of habitat (Rich et al. 2018). Understanding the spatio-temporal occurrence of large carnivores along with their preys could be used for conserving the species and populations (Davis et al. 2018) in this changing world's environment (Frey et al. 2017). However, the studies on spatial-temporal interaction between large carnivores and prey species in ecosystems have been rare (Dou et al. 2019).

Dhole, tiger, and leopard have different prey selection according to the size, shape, physiology and behavior (Steinmetz et al. 2013). There was spatial and temporal avoidance among the large carnivores to minimize competition for hunting in the area (Lovari et al. 2015). It was found that body weights of dhole prey varied in each area, for example, 40-60 kilograms (Selvan et al. 2013), while Hayward et al. (2014) found the weights were between 130-190 kilograms. Kamler et al. (2020) categorized the size of dhole prey according to their body weights by collecting study results in different areas. It showed that the majority of dhole preys were mediumsized even-toed ungulates with weight between 40-60 kilograms, and large even-toed ungulates with weight over 100 kilograms which were mostly found in the open areas of deciduous forest in India. Meanwhile, tiger would hunt large preys. Normally tiger hunts preys weighing over 176 kilograms, while leopard hunts preys weighing between 30 - 
175 kilograms (Bhattarai and Kindlmann 2012). Thus, the average weights of the main preys hunted by tiger, leopard, and dhole were 91.5, 37.6, and 43.4 kilograms respectively. This was similar to the study results in Anamalai Tiger Reserve, southern India, which showed that the approximate weight of tiger prey was 92 kilograms, the average weight of leopard prey was 37 kilograms, and the average weight of dhole prey was 36 kilograms (Kumaraguru et al. 2011).

Huai Kha Khaeng Wildlife Sanctuary, Uthai Thani Province, Thailand is the important habitat of tiger, leopard, and dhole. As such, their populations in the sanctuary need to be monitored for long-term conservation. Duangchantrasiri et al. (2016) reported that there were 1.27 to 2.09 tigers per $100 \mathrm{~km}^{2}$ in Huai Kha Khaeng Wildlife Sanctuary. This number was similar to that of many sanctuaries in India, such as Tadoba, Bhadra, Melghat, Pench, and Panna reserves (Jhala et al. 2020). In addition, Simcharoen and Duangchantrasiri (2008) reported that the approximate number of leopards in Khao Nang Rum valley of the same site was 5.98 per $100 \mathrm{~km}^{2}$, calculated by considering the habitat area using satellite radio collar. It was found that there were 6.3 leopards per $100 \mathrm{~km}^{2}$ which was the highest number when compared to the study results of other sites. Brodie and Giordano (2012) reported that the population density of leopard in Southeast Asia was approximately $0.8-1.9$ per $100 \mathrm{~km}^{2}$, while tiger populations in other countries in the Indian peninsula were between 1.0-25.5 per 100 square kilometers (Ramesh 2010).

There is concentrated interaction between large carnivores and their preys in Huai Kha Khaeng Wildlife Sanctuary. Charaspet et al. (2019) reported that the habitat area of female dhole in the sanctuary studied from satellite radiofrequency was $34 \mathrm{~km}^{2}$. Phetdee (2000) studied the prey species of large carnivores in the sanctuary and reported that there were 18 tiger prey species found using scat analysis. The preys with the highest frequency of occurrence were respectively banteng, sambar deer, red muntjac, gaur, wild boar, Malayan porcupine, Asiatic black bear. The scat was composed of grass and unidentified animal. By studying the types of leopard food in Huai Kha Khaeng Wildlife Sanctuary, Simcharoen (2008) reported that 27 types of prey were found from scat analysis with the respective highest frequencies of occurrence were sambar deer, Malayan porcupine, wild boar, red muntjac, banteng, Phayre's langur (Trachypithecus phayrei), crabeating macaque (Macaca fascicularis), white-handed gibbon (Hylobates lar), Bengal slow loris (Nycticebus bengalensis), and rhesus macaque (Macaca mulatta). Pianka's prey overlap index between dhole and leopard preys acquired from data collection in the same time period in Huai Kha Khaeng Wildlife Sanctuary was 0.98 and the index between dhole and tiger was 0.68 (Charaspet et al. 2019).

Ramesh et al. (2012) found that dhole separated the habitat on a temporal basis with tiger and leopard in the same area without any overlap. It was found that dhole had spatial overlap with leopard, but there was no spatial overlap with tiger. This situation was to decrease the chance of competition in the ecosystem resulting from the hunting of mutual prey. The study results from the spatialtemporal separation of dhole and clouded leopard (Neofelis nebulosa), the largest carnivore in Nam Et-Phou Louey National Protected Area in Laos, showed the least temporal overlap. It also revealed that dhole had significant temporal-overlap activities with potential wild prey (Rasphone et al. 2020).

Vinitpornsawan and Fuller (2020) studied the spatialtemporal utilization of habitat of tiger, leopard, dhole, and their preys in the Western Thungyai Naresuan Wildlife Sanctuary during 2010-2012 using camera traps. It was found that tiger had no temporal coexistence with leopard nor with dhole, while the spatial coexistence of leopard was related to that of dhole. It was also discovered that tiger had temporal overlap with gaur and sambar deer, while leopard had temporal overlap with red muntjac and wild boar. Dhole had temporal overlap with red muntjac and wild boar. Significant spatial overlap between tiger, leopard, and dhole was not found. The spatial-temporal coexistence of the three large carnivores resulted from the different activity times of the prey, as well as different preferences in food. There was about 1.4-1.6 tiger per $100 \mathrm{~km}^{2}$ and $0.7-$ 0.8 leopard per $100 \mathrm{~km}^{2}$ (Vinitpornsawan 2013). Nevertheless, in Huai Kha Khaeng Wildlife Sanctuary tiger populations were 2.5 times and leopard populations were 7.5 times more than those of tiger and leopard found in the Western Thungyai Naresuan Wildlife Sanctuary according to the study results of Saisamorn et al. (2019). Saisamorn et al. (2019) also reported that the difference and abundance of tiger in Huai Kha Khaeng Wildlife Sanctuary did not affect the activity times of leopard which mostly hunt during dusk and dawn. This corresponded to the activities of wild boar and red muntjac which mostly hunt at the same time as leopard, while sambar deer and banteng would avoid that time period.

Although the original scat analysis and the study of the area where prey was killed to discover the prey species of large carnivores would give good results (Kerley et al. 2015), the above study method had some restrictions which obstruct the understanding of mutual spatial-temporal characteristics of the predators and preys. Camera traps were widely used to study eating habits as they could be installed in several positions. They were used to study dhole (Kamler et al. 2020), and leopard (Saisamorn et al. 2019). It clarified more the sharing of important resources of the large carnivores in the ecosystem.

This research aimed to study (1) the abundance of dhole, tiger, leopard, and potential wild prey, and (2) the spatial-temporal overlap between dhole, tiger, leopard, and the potential wild prey in Huai Kha Khaeng Wildlife Sanctuary, Thailand. There were three hypotheses tested in this study: (1) the spatial overlap between dhole and leopard was higher in comparison to dhole and tiger because dhole and leopard had higher prey overlap, (2) the temporal overlap for avoidance was not found between the three carnivores, and (3) the spatial-temporal overlap of dhole and the potential wild prey was higher compared to those of tiger and leopard. 


\section{MATERIALS AND METHODS}

\section{Study area}

Huai Kha Khaeng Wildlife Sanctuary, Thailand covers about 2,800 square kilometers. It is located between $15^{\circ}$ $15^{\prime}-15^{\circ} 45^{\prime} \mathrm{N}$ latitude and $99^{\circ} 5^{\prime}-99^{\circ} 25^{\prime} \mathrm{E}$ longitude. It is a part of Thung Yai-Huai Kha Khaeng which was announced as part of the World's Natural Heritage in 1990 as it contains a variety of plant and wild animal species due to the niche overlap of 3 zoogeographic regions (Western Forest Complex 2004). The study area ranged in elevation from 160 to $1,687 \mathrm{~m}$ above sea level (m asl.) but the dominant elevation varied from 200-500 m asl., and slopes were generally moderate $(15 \% 30 \%)$. The major vegetation types include mixed deciduous combined with bamboo $(48.3 \%)$, dry evergreen $(27.5 \%)$, tropical hill evergreen forest $(9.6 \%)$, savannah grassland $(7.3 \%)$, agriculture $(4.0 \%)$, and dry dipterocarp forest $(2.2 \%)$ (Western Forest Complex 2004). The annual temperatures of the HKKWS range between $8-38^{\circ} \mathrm{C}$ with the lowest temperature in January and the highest temperature in April. Mean annual rainfall is $1,375 \mathrm{~mm}$. The dry season is from November to April with a mean monthly rainfall of $298 \mathrm{~mm}$, while the wet season is from May to October with a mean monthly rainfall of 1,088 mm (Western Forest Complex 2004). Huai Kha Khaeng Wildlife Sanctuary is known as the home of top carnivores including tiger, leopard, and dhole as well as important herbivores including gaur, banteng, sambar deer, wild boar, and red muntjac (Western Forest Complex 2004). The location of Huai Kha Khaeng Wildlife Sanctuary, the study site and the camera trap locations are shown in Figure 1.

\section{Data collection}

The data were collected in Huai Kha Khaeng Wildlife Sanctuary, Uthai Thani, during November 2017-2019 with 20 sets of automatic camera traps (Trail Camera Model Essential E3 16MP resolution) which were switched and installed in 192 positions for 6,596 trap nights. The data collection is described below.

The map defines 1 grid square for 1 square kilometer in a 1:50,000 scale topographic map. One camera trap was installed per 1 grid square (Roveroa et al. 2013). Each camera was set in each set of 15-20 grid squares for 30 days before moving and setting them in new positions. Generally, each camera in each position was set over 500 meters apart for the independence of photos in each grid square. It decreased the possibility of taking photos of the same individual animal with many cameras.

The positions of the cameras would be chosen based on the optimum conditions of each site, such as animal trails and traces, carnivore traces, and records of the surroundings, such as plant communities, roads, trails, inspections, permanent streams, salt earth, water wells, and forest protection units (Lynam et al. 2013).
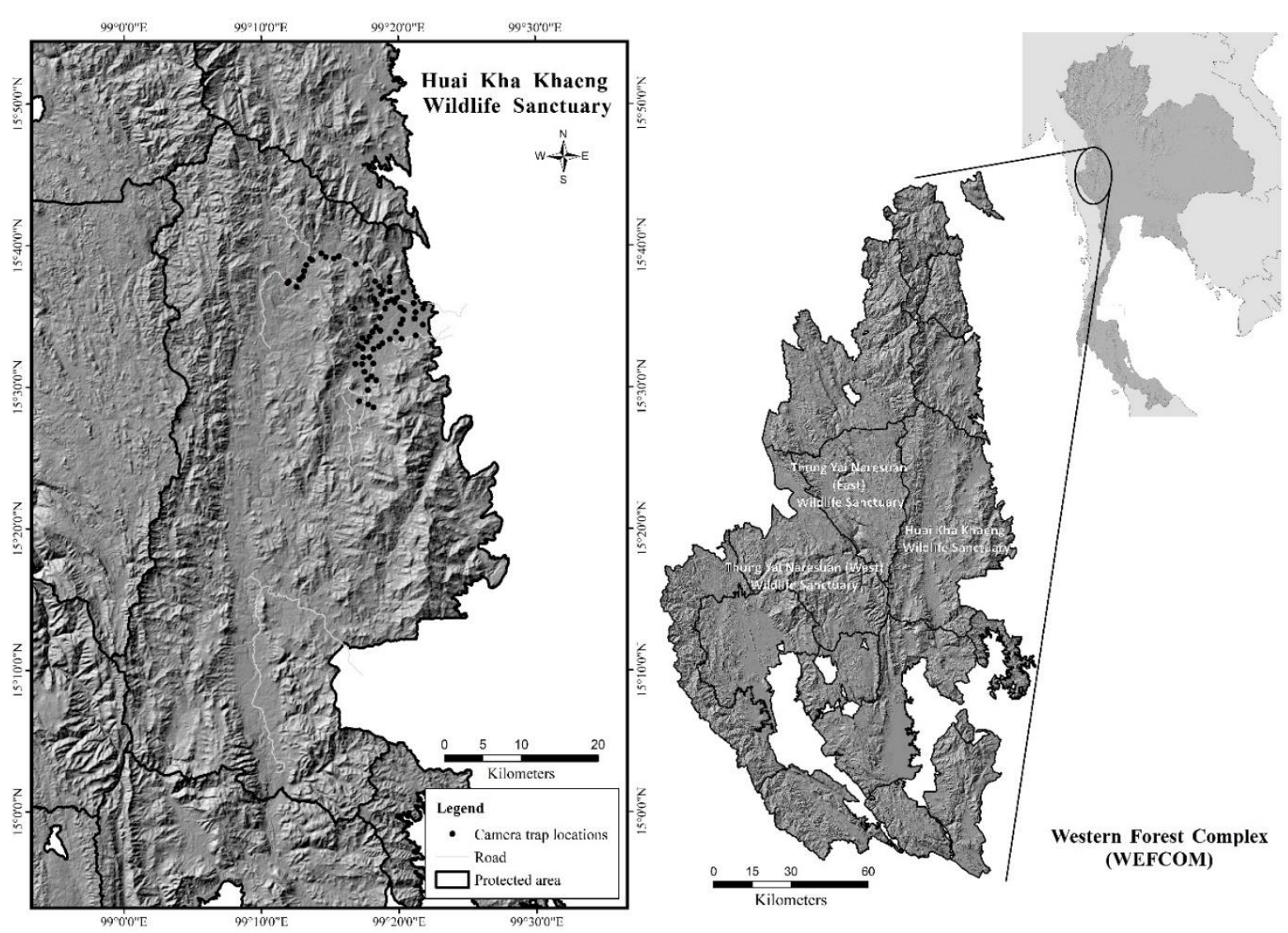

Figure 1. Map of Huai Kha Khaeng Wildlife Sanctuary, Thailand and the camera trap locations ( $\mathrm{n}=192$ with 6,596 trap nights totally). (Source: Department of Land Development 2016) 
The cameras were installed about 30-40 centimeters above the ground and 3-4 meters away from the target area, or at the optimum site of the area. Photos were automatically captured when the sensor system detecting movement. Three photos were taken every 10 seconds throughout 24 hours (Oliver et al. 2017). The cameras were installed for 30 days. After that, they were moved to new areas. GPS was used to record the cameras' positions. The initial material for the analysis was the resulting photographs in JPG format. The unloading, storage, sorting, and initial processing of images were carried out with the help of Camera Trap Manager Programme. The photos were transferred from disks to computers, and categorized using Camera Trap Manager (Zaragozi et al. 2015) before being imported to Microsoft Excel for further data analysis.

\section{Statistical analysis}

The carnivores were categorized based on the photos taken as evidence. Their common names and scientific names referring to Francis (2019). A photo with clear identification of date and time, and a photo with more than one carnivore was counted as one event. It was a photo or an event that was independent. The criteria for independence of animal photographs were: (i) continuous shots of the same or different individual animals; (ii) continuous photos of the same animal of the same species which were taken 30 minutes apart, and (iii) discontinuous photos of the same animal of the same species (Choo et al. 2020).

The information of their hunting times could be determined from the cameras by collecting information and categorizing the species. Day time was during 06:01-17:59 and night time was during 18:00-06:00 ( $\mathrm{Bu}$ et al. 2016). The information was plotted to create a graph of hunting times of carnivores and other wild prey in order to categorize the carnivore species according to the time identified in the photos. There were 5 different groups (Frey et al. 2017). In other words, if the number of their photos taken at night was over $85 \%$, they were categorized in the strongly nocturnal group. If the number of their photos taken at night was $61 \%-84 \%$, they were categorized in the mostly nocturnal group. If the number of their photos taken at night and daytime was within $40 \%-60 \%$, they were categorized in the cathemeral group. If the number of their photos taken in daytime was within $61 \%-84 \%$, they were categorized in the mostly diurnal group. If the number of their photos taken during daytime was over $85 \%$, they were categorized in the strongly diurnal group. Spatial-temporal coexistence was analyzed using the position where the camera traps had detected the appearance (1) and disappearance $(0)$ of wild animals and the times when wild animals were found each hour within the day. It was used to calculate rank correlation based on Spearman's rank correlation coefficient with SPSS (IBM Corp. Released 2016). The results were investigated at significance levels of $\mathrm{P} \leq 0.05$ and $\mathrm{P} \leq 0.01$.

The average time when the animals were photographed could be analyzed using independent photos at a $95 \%$ confidence interval with ORIANA version 4.02 (Kovach
2011). The Watson $U^{2}$ test was used to test the difference of coexistence time by particularly considering the results at the $\mathrm{P}<0.05$ significance level. The carnivore activity time was analyzed with R program (Meredith and Ridout 2020) and circular packages (Agostinelli and Lund 2017) in order to compare the activity times of dhole, large carnivores, and between carnivores and the potential prey in Huai Kha Khaeng Wildlife Sanctuary. It was understood by calculating the temporal overlap coefficient $(\Delta)$ by Kernel density function (Węglarczyk 2017) in order to find the overlap degree for which 1 referred to the complete overlap and 0 referred to no overlap. The overlap coefficient was calculated using $\Delta 1$ when there is little data, and using $\Delta 4$ when there were over 50 data items (Meredith and Ridout 2020). The accuracy of the study was acquired from the calculation at a 95\% confidence interval from 10,000 bootstrap samples. The temporal overlap degree was considered based on Lynam et al. (2013) who defined that if the overlap coefficient was $\leq 0.5$, the overlap level was low; if the overlap coefficient was within $0.5-0.75$, the overlap level was moderate; if the overlap coefficient was $\geq 0.75$, the overlap level was high

The overlap index between the potential preys could be calculated from the coexistence in each camera position, and the appearance at different times by hour within the day between dhole, tiger, and leopard, and the potential prey. The overlap index of the three large carnivores could be calculated from the temporal overlap coefficient in order to consider the overlap with the potential prey species based on Pianka's prey overlap index (Davis et al. 2015) according to the formula below.

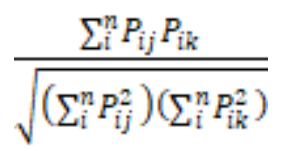

Where; $P_{i j}$ is the percentage of prey species $\mathrm{i}$ of predator $\mathrm{j}, P_{i k}$ is the percentage of prey species $\mathrm{i}$ of predator k. Pianka's index varies between 0 (total separation) and 1 (total overlap). We used this index to enable comparisons with other studies. Analysis of niche overlap between the most common species was based on classical Pianka's index (Davis et al. 2015). The $\mathrm{R}$ program (Meredith and Ridout 2020) and SPAA-package or Species Association Analysis package (Zhang 2016) were used for the analysis.

\section{RESULTS AND DISCUSSION}

The study results from the camera traps showed that 49 species of wild animals were found (Table 1).

All three species of large carnivorous mammals being the focus of this study (i.e., dhole, tiger, and leopard) were recorded. Apart from the three large carnivores, there were 17 species of carnivorous mammals widely found included large Indian civet (Viverra zibetha), leopard cat (Prionailurus bengalensis), crab-eating mongoose (Herpestes urva), Asiatic black bear, mask-palm civet (Paguma larvata), small Indian civet (Viverricula indica), etc. 
Table 1 The abundance of three large carnivores (i.e., dhole, tiger, leopard) and their potential preys in Huai Kha Khaeng Wildlife Sanctuary, from 192 camera traps during November 2017-March 2020, totaling 6,596 trap nights.

\begin{tabular}{|c|c|c|c|c|}
\hline Common name & Scientific name & No. of picture & No. of location & RAI (\%) \\
\hline \multicolumn{5}{|l|}{ Large predators } \\
\hline Dhole & Cuon alpinus & 83 & 46 & 1.26 \\
\hline Tiger & Panthera tigris & 242 & 99 & 3.67 \\
\hline Leopard & Panthera pardus & 637 & 161 & 9.66 \\
\hline \multicolumn{5}{|l|}{ Non-carnivorous mammals } \\
\hline Sambar deer & Rusa unicolor & 2,189 & 140 & 33.19 \\
\hline Red muntjac & Muntiacus muntjak & 907 & 135 & 13.75 \\
\hline Malayan porcupine & Hystrix brachyura & 803 & 124 & 12.17 \\
\hline Wild pig & Sus scrofa & 718 & 139 & 10.89 \\
\hline Banteng & Bos javanicus & 467 & 88 & 7.08 \\
\hline Rat/mouse spp. & Muridae & 57 & 14 & 0.88 \\
\hline Gaur & Bos gaurus & 45 & 14 & 0.68 \\
\hline Malayan tapir & Tapirus indicus & 36 & 17 & 0.55 \\
\hline Pig-tailed macaque & Macaca nemestrina & 25 & 20 & 0.38 \\
\hline Crab-eating macaque & Macaca fascicularis & 24 & 11 & 0.36 \\
\hline Rhesus macaque & Macaca mulatta & 17 & 10 & 0.26 \\
\hline Grey-bellied squirrel & Callosciurus caniceps & 8 & 3 & 0.12 \\
\hline Hog deer & Axis porcinus & 7 & 2 & 0.11 \\
\hline Bamboo rat & Rhizomys sumatrensis & 5 & 3 & 0.08 \\
\hline Pangolin & Manis javanica & 4 & 2 & 0.06 \\
\hline Northern tree shrew & Tupaia belangeri & 3 & 3 & 0.00 \\
\hline Asiatic brush-tailed porcupine & Atherurus macrourus & 2 & 1 & 0.03 \\
\hline Serow & Capricornis sumatraensis & 2 & 2 & 0.03 \\
\hline Finlayson's squirrel & Callosciurus finlaysonii & 1 & 1 & 0.02 \\
\hline Black giant squirrel & Ratufa bicolor & 1 & 1 & 0.02 \\
\hline \multicolumn{5}{|l|}{ Carnivorous mammals } \\
\hline Large Indian civet & Viverra zibetha & 862 & 110 & 13.07 \\
\hline Asiatic jackal & Canis aureus & 784 & 93 & 11.89 \\
\hline Common palm civet & Paradoxurus hermaphroditus & 526 & 76 & 7.97 \\
\hline Leopard cat & Prionailurus bengalensis & 207 & 67 & 3.14 \\
\hline Crab-eating mongoose & Herpestes urva & 78 & 37 & 1.18 \\
\hline Asian black bear & Ursus thibetanus & 32 & 20 & 0.49 \\
\hline Mask-palm civet & Paguma larvata & 23 & 15 & 0.35 \\
\hline Small Indian civet & Viverricula indica & 23 & 17 & 0.35 \\
\hline Malayan sun bear & Ursus malayanus & 19 & 16 & 0.29 \\
\hline Yellow-throated marten & Martes flavigula & 13 & 10 & 0.20 \\
\hline Large spotted civet & Viverra megaspila & 8 & 6 & 0.12 \\
\hline Hog badger & Arctonyx collaris & 7 & 6 & 0.11 \\
\hline Asian golden cat & Catopuma temminckii & 2 & 2 & 0.03 \\
\hline Clouded leopard & Neofelis nebulosa & 2 & 2 & 0.03 \\
\hline Banded linsang & Prionodon linsang & 2 & 2 & 0.03 \\
\hline Binturong & Arctictis binturong & 1 & 1 & 0.02 \\
\hline Small Indian mongoose & Herpestes javanicus & 1 & 1 & 0.02 \\
\hline \multicolumn{5}{|l|}{ Birds } \\
\hline Kalij pheasant & Lophura leucomelanos & 2 & 1 & 0.03 \\
\hline Silver pheasant & Lophura nycthemera & 1 & 1 & 0.02 \\
\hline Brown fish owl & Ketupa zeylonensis & 7 & 2 & 0.01 \\
\hline Red jungle fowl & Gallus zygogenesis & 327 & 53 & 4.96 \\
\hline Green peafowl & Pavo muticus & 506 & 84 & 7.67 \\
\hline \multicolumn{5}{|l|}{ Reptiles } \\
\hline Bengal monitor & Varanus bengalensis & 68 & 15 & 0.42 \\
\hline Asian water monitor & Varanus salvator & 12 & 11 & 0.24 \\
\hline Butterfly lizard & Leiolepis belliana & 12 & 2 & 0.18 \\
\hline Elongated tortoise & Indotestudo elongata & 2 & 2 & 0.03 \\
\hline
\end{tabular}

There were also 20 species of non-carnivorous mammals found from the camera traps, including those with the highest abundance such as sambar deer, red muntjac, Malayan porcupine, wild boar, banteng, gaur, Malayan tapir (Tapirus indicus), pig-tailed macaque
(Macaca nemestrina), crab-eating macaque (Macaca fascicularis), rhesus macaque (Macaca mulatta), etc. Five species of bird were Kalij pheasant (Lophura leucomelanos), silver pheasant (Lophura nycthemera), red jungle fowl, brown fish owl (Ketupa zeylonensis), and 
green peafowl (Pavo muticus). Four species of reptile found were elongated tortoise (Indotestudo elongate), Asian water monitor (Varanus salvator), Bengal monitor (Varanus bengalensis), and butterfly lizards (Leiolepis belliana). Among the three species of large carnivorous mammals, leopard had the highest relative abundance index (RAI) of $9.66 \%$, followed by tiger $3.67 \%$, and dhole $1.26 \%$ (Table 1).

\section{Spatial-temporal overlap}

By studying Table 2, there were 20 species with fewer than 10 independent photos, including grey-bellied squirrel (Callosciurus caniceps), hog deer (Axis porcinus), bamboo rat (Rhizomys sumatrensis), Malayan pangolin (Manis javanica), northern tree shrew (Tupaia belangeri), Asiatic brush-tailed porcupine (Atherurus macrourus), serow (Capricornis sumatraensis), Finlayson's squirrel (Callosciurus finlaysonii), black giant squirrel (Ratufa bicolor), large spotted civet (Viverra megaspila), hog badger (Arctonyx collaris), Asian golden cat (Catopuma temminckii), clouded leopard (Neofelis nebulosa), banded linsang (Prionodon linsang), binturong (Arctictis binturong), Small Indian mongoose (Herpestes javanicus), Kalij pheasant, silver pheasant, brown fish owl, and elongated tortoise. These were not included in the spatialtemporal analysis of this study due to too small sample size and show negligible correlation.

\section{Dhole}

The dhole's spatial overlap with tiger and leopard was positive and greatly significant. The temporal overlap was found to be significantly negative with tiger which signified the avoidance of tiger. Although dhole had significant spatial overlap with leopard, temporal overlap with leopard was not significantly found.

Dhole simultaneously had positive spatial-temporal overlap with four species of potential prey: Red muntjac, wild boar, yellow-throated marten (Martes flavigula), and red jungle fowl. Even though there was no positive spatial overlap, there was negative temporal overlap with other six species of wild animals: Sambar deer, Malayan porcupine, large Indian civet, masked palm civet, Asiatic black bear, and leopard cat. In the meantime, negative spatial-temporal overlap with banteng was found as shown in Table 2.

Table 2. The spatial-temporal overlap of appearance found from the camera traps of dhole with tiger, and leopard, as well as the potential prey from the calculation of Spearman rank correlation and Pianka's overlap index in Huai Kha Khaeng Wildlife Sanctuary (** $\mathrm{P}<0.01, * \mathrm{P}<0.05)$

\begin{tabular}{|c|c|c|c|c|}
\hline \multirow{2}{*}{ Variables } & \multicolumn{2}{|c|}{ Spatial correlation } & \multicolumn{2}{|c|}{ Temporal correlation } \\
\hline & Spearman rank test & Overlap index & Spearman rank test & Overlap index \\
\hline \multicolumn{5}{|l|}{ Large felid } \\
\hline Tiger & $0.43 * *$ & 0.58 & $-0.66 * *$ & 0.36 \\
\hline Leopard & $0.48 * *$ & 0.62 & ns & 0.66 \\
\hline \multicolumn{5}{|l|}{ Other species } \\
\hline Sambar deer & $0.33 * *$ & 0.40 & $-0.47 *$ & 0.47 \\
\hline Red muntjac & $0.27 * *$ & 0.47 & $0.82 * *$ & 0.94 \\
\hline Malayan porcupine & $0.32 * *$ & 0.58 & $-0.72 * *$ & 0.08 \\
\hline Wild pig & $0.29 * *$ & 0.42 & $0.76^{* *}$ & 0.86 \\
\hline Banteng & $-0.16^{*}$ & 0.07 & $-0.52 * *$ & 0.43 \\
\hline Large indian civet & $0.33 * *$ & 0.59 & $-0.74 * *$ & 0.09 \\
\hline Mask-palm civet & $0.18^{*}$ & 0.24 & $-0.62 * *$ & 0.15 \\
\hline Yellow-throated marten & $0.22 * *$ & 0.33 & $0.51 * *$ & 0.74 \\
\hline Red jungle fowl & $0.25 * *$ & 0.35 & $0.78 * *$ & 0.82 \\
\hline Asiatic black bear & $0.27 * *$ & 0.31 & $-0.40 *$ & 0.21 \\
\hline Leopard cat & $0.20 * *$ & 0.50 & $-0.68 * *$ & 0.13 \\
\hline Bamboo rat & $0.18^{*}$ & 0.34 & ns & 0.05 \\
\hline Northern tree shew & $0.18 *$ & 0.33 & ns & 0.28 \\
\hline Common palm civet & ns & 0.11 & $-0.81 * *$ & 0.10 \\
\hline Rat/mouse spp. (Muridae) & $\mathrm{ns}$ & 0.26 & $-0.81 * *$ & 0.08 \\
\hline Green peafowl & ns & 0.20 & $0.81 * *$ & 0.89 \\
\hline Crab-eating macaque & $\mathrm{ns}$ & 0.13 & $0.79 * *$ & 0.78 \\
\hline Siamese hare & ns & 0.04 & $-0.76 * *$ & 0.08 \\
\hline Small indian civet & ns & 0.18 & $-0.76 * *$ & 0.06 \\
\hline Asiatic jackal & ns & 0.23 & $-0.72 * *$ & 0.32 \\
\hline Pig-tailed macaque & ns & 0.23 & $0.71 * *$ & 0.72 \\
\hline Malayan tapir & $\mathrm{ns}$ & 0.19 & $-0.67 * *$ & 0.12 \\
\hline Bengal monitor & $\mathrm{ns}$ & 0.21 & $0.63 * *$ & 0.67 \\
\hline Water monitor & $\mathrm{ns}$ & 0.12 & $0.61 * *$ & 0.64 \\
\hline Buterfly lizard & $\mathrm{ns}$ & 0.00 & $0.56 * *$ & 0.57 \\
\hline Grey-bellied squirrel & $\mathrm{ns}$ & 0.05 & $0.50 * *$ & 0.60 \\
\hline Crab-eating moongoose & $\mathrm{ns}$ & 0.29 & $0.50 * *$ & 0.76 \\
\hline Rhesus macaque & $\mathrm{ns}$ & 0.06 & $0.48^{*}$ & 0.54 \\
\hline
\end{tabular}


It was found that dhole had a single significant spatial overlap, or a single significant temporal overlap with the potential prey. The solely significant spatial overlap was found in 3 species: Leopard cat, bamboo rat, and northern tree shrew. The solely significant temporal overlap of dhole found that dhole had significant positive temporal overlap with 9 other wild animals: Green peafowl, crab-eating macaque, pig-tailed macaque, Bengal monitor, Asian water monitor, butterfly lizards, grey-bellied squirrel, crab-eating mongoose, and rhesus macaque. The significant negative temporal overlap was found with other six species of wild animals: Malayan tapir, Siamese hare (Lepus peguensis), small indian civet, common palm civet (Paradoxurus hermaphroditus), and rat/mouse spp. (Muridae) as shown in Table 2.

\section{Tiger}

Tiger had great significant spatial overlap of appearance with dhole (0.43) and leopard (0.48). The negative spatial overlap was greatly significant with dhole $(-0.66)$. For the potential prey, it was found that tiger had great significant spatial-temporal overlap with 5 species of wild animals: large Indian civet, Malayan Tapir, sambar deer, Malayan porcupine, and Asiatic black bear.

By solely considering spatial overlap with the potential prey, it was found that tiger had the overlap with three species of wild animals: gaur, yellow-throated marten, and northern tree shrew. It was found that tiger had only temporal overlap with 16 species of potential prey: common palm civet, crab-eating mongoose, Siamese hare, banteng, crab-eating macaque, rat/mouse spp. (Muridae), Bengal monitor, Asian water monitor, masked palm civet, Asiatic jackal, butterfly lizards, rhesus macaque, Malayan sun bear, small Indian civet, green peafowl.

The spatial-temporal overlap of tiger with dhole and leopard, as well as the potential wild-animal prey of tiger was shown in Table 3.

\section{Leopard}

Leopard had great significant spatial overlap with dhole and tiger. However, the temporal appearance of leopard was not significant with dhole and tiger. It signified that they were living in the same area while avoiding the same hunting time. Spatial-temporal overlap of leopard with the potential prey was not significantly found. It was found that leopard had significant spatial overlap with 11 species of the potential wild animal prey: Large Indian civet, Malayan porcupine, Asiatic jackal (Canis aureus), sambar deer, yellow-throated marten, red jungle fowl, red muntjac, wild boar, green peafowl, common palm civet, and bamboo rat. Significant temporal overlap was found with gaur, butterfly lizard, grey-bellied squirrel, and rhesus macaque as shown in Table 4.

\section{The spatial-temporal overlap of dhole, tiger, leopard, and other wild animals}

The species of wild animals with significant spatialtemporal overlap with dhole, tiger, and leopard, as well as dhole prey species from the study of Charaspet et al. (2020); Khoewsree et al. (2020), and Kamler et al. (2020); prey species of tiger from the study of Phetdee (2000), and prey species of leopard from the study of Simcharoen (2008) were studied to understand the potential wild animal prey of the large carnivores. It was found that there were 11 species of wild animals with significant spatial overlap with dhole, tiger, and leopard. They were large Indian civet, sambar deer, Malayan porcupine, wild boar, red muntjac, Asiatic black bear, red jungle fowl, banteng, gaur, Malayan tapir, and pig-tailed macaque. However, it was not found that Malayan tapir was the food of tiger and leopard referring to the list of prey species from the documents of Phetdee (2000) and Simcharoen (2008). There, Malayan Tapir was removed from the potential prey of the large carnivores in the study site. Dhole had great significant spatial overlap with tiger $(0.43, \mathrm{P}<0.01)$ and leopard $(0.48, \mathrm{P}<0.01)$. Tiger had great overlap with leopard $(0.56, \mathrm{P}<0.01)$. By considering the spatial overlap of the potential wild animal prey, it was found that dhole, tiger, and leopard had spatial overlap with five species of potential prey: Large Indian civet, sambar deer, Malayan porcupine, wild boar, and red muntjac. It was revealed that nine species of the potential prey had temporal overlap with tiger and dhole, while leopard had significant temporal overlap solely with gaur. The details were as shown in Table 5.

\section{Daily activity patterns}

The study of daily activity patterns showed that the activity time modes of dhole, tiger, and leopard were at 10.50 hrs., 23.42 hrs., and 22.39 hrs., respectively (Table $6)$. The levels of overlap between dhole, tiger, and leopard resulted from the avoidance. It confirmed the study of temporal overlap which found the insignificant overlap between tiger and leopard; leopard and dhole. However, the temporal overlap between dhole and tiger was significantly opposite $(-0.66, \mathrm{P}<0.01)$. It signified the great avoidance of the three large carnivores although they were living in the same site where the spatial overlap was found.

Five species of potential prey of the three large carnivorous wild animals appeared on average at night (MN, SN), which were sambar deer, gaur, banteng, Malayan porcupine, and Malayan tapir. There were four species that appeared during day time (MD, SD), which were red muntjac, wild boar, pig-tailed macaque, and red jungle fowl. However, gaur was active during day and night times (CA) as shown in Table 6.

The calculation showed that the dhole activity mode was at 10.55 hrs. It was mostly found in the daytime. Dhole was large and strongly diurnal carnivores. Tiger activity mode was at 23.42 hrs. Leopard was cathemeral animals, but their activity mode was at $22.39 \mathrm{hrs}$. It was revealed that the standard error of the time when leopard was found was the highest. It means that the hunting activity of leopards at the site varied to a greater extent than that of the two large predators. In the meantime, dhole was found hunting in the daytime to avoid jostling for food with tiger and leopard. Most of the large carnivores' prey appeared at night, except red muntjac, wild boar, pig-tailed macaque, and red jungle fowl, while other species were hunted at night the same as tiger and leopard. 
Table 3. The spatial-temporal overlap of appearance found from the camera traps of tiger with dhole, and leopard, as well as the potential prey from the calculation of Spearman rank correlation and Pianka's overlap index in Huai Kha Khaeng Wildlife Sanctuary (** $\mathrm{P}<0.01, * \mathrm{P}<0.05)$

\begin{tabular}{|c|c|c|c|c|}
\hline \multirow{2}{*}{ Variables } & \multicolumn{2}{|c|}{ Spatial correlation } & \multicolumn{2}{|c|}{ Temporal correlation } \\
\hline & Spearman rank test & Overlap index & Spearman rank test & Overlap index \\
\hline \multicolumn{5}{|l|}{ Large carnivores } \\
\hline Dhole & $0.43 * *$ & 0.58 & $-0.66 * *$ & 0.36 \\
\hline Leopard & $0.56^{* *}$ & 0.67 & ns & 0.86 \\
\hline \multicolumn{5}{|l|}{ Other species } \\
\hline Large Indian civet & $0.55^{* *}$ & 0.67 & $0.76^{* *}$ & 0.88 \\
\hline Malayan tapir & $0.29 * *$ & 0.28 & $0.66^{* *}$ & 0.72 \\
\hline Sambar deer & $0.33^{* *}$ & 0.52 & $0.65 * *$ & 0.90 \\
\hline Red muntjac & $0.42 * *$ & 0.72 & $-0.58 * *$ & 0.51 \\
\hline Malayan porcupine & $0.41 * *$ & 0.59 & $0.51 * *$ & 0.83 \\
\hline Red jungle fowl & $0.30 * *$ & 0.32 & $-0.48 *$ & 0.43 \\
\hline Pig-tailed macaque & $0.23 * *$ & 0.28 & $-0.48 *$ & 0.33 \\
\hline Asiatic black bear & $0.23 * *$ & 0.32 & $0.47^{*}$ & 0.71 \\
\hline Wild boar & $0.31 * *$ & 0.54 & $-0.43 * *$ & 0.59 \\
\hline Yellow-throated marten & $0.26^{* *}$ & 0.30 & ns & 0.38 \\
\hline Gaur & $0.25^{* *}$ & 0.35 & ns & 0.71 \\
\hline Northern tree shrew & $0.24 * *$ & 0.33 & ns & 0.34 \\
\hline Common palm civet & ns & 0.31 & $0.85^{* *}$ & 0.89 \\
\hline Crab-eating macaque & ns & 0.25 & $-0.80 * *$ & 0.20 \\
\hline Siamese hare & ns & 0.16 & $0.76^{* *}$ & 0.87 \\
\hline Banteng & ns & 0.24 & $0.71 * *$ & 0.91 \\
\hline Rhesus macaque & ns & 0.08 & $-0.67 * *$ & 0.13 \\
\hline Rat/mouse (Muridae) & ns & 0.30 & $0.64 * *$ & 0.78 \\
\hline Bengal monitor & ns & 0.12 & $-0.59 * *$ & 0.24 \\
\hline Water monitor & ns & 0.14 & $-0.57 * *$ & 0.25 \\
\hline Mask palm civet & ns & 0.39 & $0.57 * *$ & 0.75 \\
\hline Asiatic jackal & ns & 0.34 & $0.56^{* *}$ & 0.90 \\
\hline Butterfly lizard & ns & 0.00 & $-0.49 * *$ & 0.20 \\
\hline Green peafowl & ns & 0.42 & $-0.49 * *$ & 0.42 \\
\hline Small indian civet & ns & 0.18 & $0.47 * *$ & 0.67 \\
\hline Bamboo rat & ns & 0.16 & $0.46^{* *}$ & 0.50 \\
\hline Crab eating moongoose & ns & 0.39 & $-0.45^{*}$ & 0.37 \\
\hline Malayan sun bear & ns & 0.34 & $0.43 * *$ & 0.69 \\
\hline
\end{tabular}

Table 4 The spatial-temporal overlap of appearance found from the camera traps of leopard with dhole, and tiger, as well as the potential prey from the calculation of Spearman rank correlation and Pianka's overlap index in Huai Kha Khaeng Wildlife Sanctuary (** $\mathrm{P}<0.01, * \mathrm{P}<0.05)$

\begin{tabular}{lcccc}
\hline \multirow{2}{*}{ Variables } & \multicolumn{2}{c}{ Spatial correlation } & \multicolumn{2}{c}{ Temporal correlation } \\
\cline { 2 - 5 } & Spearman rank test & Overlap index & Spearman rank test & Overlap index \\
\hline Large carnivores & & & & \\
Dhole & $0.48^{* *}$ & 0.62 & $\mathrm{~ns}$ & 0.66 \\
Tiger & $0.56^{* *}$ & 0.67 & $\mathrm{~ns}$ & 0.86 \\
Other species & & & \\
Large indian civet & $0.51^{* *}$ & 0.60 & $\mathrm{~ns}$ & 0.67 \\
Malayan porcupine & $0.44^{* *}$ & 0.56 & $\mathrm{~ns}$ & 0.63 \\
Asiatic jackal & $0.38^{* *}$ & 0.50 & $\mathrm{~ns}$ & 0.80 \\
Sambar deer & $0.35^{* *}$ & 0.47 & $\mathrm{~ns}$ & 0.90 \\
Yellow-throated marten & $0.28^{* *}$ & 0.28 & $\mathrm{~ns}$ & 0.56 \\
Red jungle fowl & $0.27^{* *}$ & 0.48 & $\mathrm{~ns}$ & 0.74 \\
Red muntjac & $0.26^{* *}$ & 0.54 & $\mathrm{~ns}$ & 0.79 \\
Wild boar & $0.25^{* *}$ & 0.50 & $\mathrm{~ns}$ & 0.85 \\
Green peafowl & $0.23^{* *}$ & 0.36 & $\mathrm{~ns}$ & 0.71 \\
Common palm civet & $0.17^{*}$ & 0.36 & $\mathrm{~ns}$ & 0.68 \\
Bamboo rat & $0.16^{*}$ & 0.20 & $\mathrm{~ns}$ & 0.35 \\
Gaur & $\mathrm{ns}$ & 0.23 & $0.50^{* *}$ & 0.82 \\
Butterfly lizard & $\mathrm{ns}$ & 0.02 & $-0.47^{*}$ & 0.41 \\
Grey-bellied squirrel & $\mathrm{ns}$ & 0.04 & $-0.40^{*}$ & 0.53 \\
Rhesus macaque & $\mathrm{ns}$ & 0.08 & & 0.38 \\
\hline
\end{tabular}


Table 5. The analysis of spatial-temporal overlap from calculation using Spearman rank correlation of dhole, tiger, leopard, and the potential wild animal prey in Huai Kha Khaeng Wildlife Sanctuary, from the camera traps $(* * \mathrm{P}<0.01, * \mathrm{P}<0.05)$

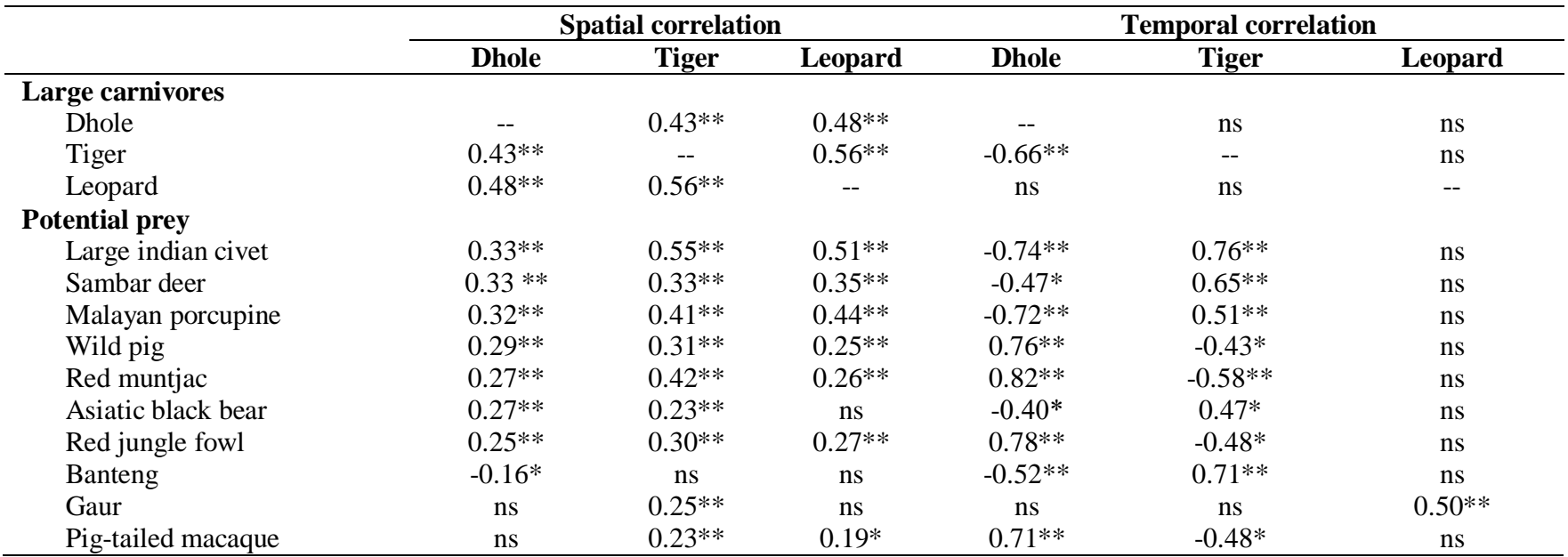

Table 6. The activity times of dhole, tiger, leopard, and potential wild animal prey acquired from the camera traps in 192 positions in Huai Kha Khaeng Wildlife Sanctuary, during November 2017-March 2019

\begin{tabular}{|c|c|c|c|c|c|}
\hline Species & $\left.\mathbf{N}^{1}\right)$ & Mean hour (degree) & SE (degree) & $\%$ day time & Activities pattern ${ }^{2}$ ) \\
\hline \multicolumn{6}{|l|}{ Large carnivores } \\
\hline Dhole & 83 & $10: 55\left(163.97^{\circ}\right)$ & $00: 26\left(6.58^{\circ}\right)$ & 93.67 & SD \\
\hline Tiger & 242 & $23: 42\left(355.50^{\circ}\right)$ & $00: 31\left(7.98^{\circ}\right)$ & 25.10 & $\mathrm{MN}$ \\
\hline Leopard & 637 & $22: 39\left(339.91^{\circ}\right)$ & $02: 22\left(35.52^{\circ}\right)$ & 50.24 & $\mathrm{CA}$ \\
\hline \multicolumn{6}{|l|}{ Potential prey } \\
\hline Sambar deer & 2,189 & $02: 33\left(38.30^{\circ}\right)$ & $00: 11\left(2.92^{\circ}\right)$ & 31.39 & MN \\
\hline Red muntjac & 907 & $10: 43\left(160.90^{\circ}\right)$ & $00: 12\left(3.12^{\circ}\right)$ & 80.92 & MD \\
\hline Gaur & 45 & $22: 53\left(343.33^{\circ}\right)$ & $02: 43\left(40.99^{\circ}\right)$ & 48.65 & CA \\
\hline Banteng & 467 & $23: 33\left(353.46^{\circ}\right)$ & $00: 28\left(7.04^{\circ}\right)$ & 32.47 & $\mathrm{MN}$ \\
\hline Wild pig & 718 & $12: 48\left(192.18^{\circ}\right)$ & $00: 16\left(4.06^{\circ}\right)$ & 75.53 & MD \\
\hline Pig-tailed macaque & 25 & $12: 27\left(186.87^{\circ}\right)$ & $00: 38\left(9.66^{\circ}\right)$ & 96.00 & SD \\
\hline Malayan porcupine & 780 & $23: 40\left(355.21^{\circ}\right)$ & $00: 07\left(1.87^{\circ}\right)$ & 5.13 & SN \\
\hline Large indian civet & 856 & $00: 15\left(3.85^{\circ}\right)$ & $00: 08\left(2.03^{\circ}\right)$ & 4.59 & SN \\
\hline Asiatic black bear & 26 & $23: 49\left(357.46^{\circ}\right)$ & $01: 42\left(25.62^{\circ}\right)$ & 33.33 & $\mathrm{MN}$ \\
\hline Red jungle fowl & 327 & $11: 20\left(170.04^{\circ}\right)$ & $00: 18\left(4.72^{\circ}\right)$ & 89.60 & SD \\
\hline
\end{tabular}

Note: 1) Independent photo. 2) The daily activity of species was classified based on the percentage of diurnal activity (06:00-17:59): SD $=$ strongly diurnal $(\geq 85 \%), \mathrm{MD}=$ mostly diurnal $(84-61 \%), \mathrm{CA}=$ cathemeral $(60-40 \%), \mathrm{MN}=$ mostly nocturnal $(39-16 \%)$ and $\mathrm{SN}=$ strongly nocturnal $(\leq 15 \%)$ (van Schaik and Griffiths 1996)

It was noticeable that gaur was a prey animal with high variance of appearance which signified that its uncertainty of appearance was higher than other prey. It corresponded with leopard which also had high variance of appearance. It was also found that leopard had significant temporal appearance with gaur which was the only prey species. By comparing the appearance between the large carnivores and prey with Watson's $\mathrm{U}^{2}$ test, it was discovered that the appearance of dhole was not different from only two prey species: pig-tailed macaque $\left(\mathrm{U}^{2}=0.094, \mathrm{P}>0.20\right)$ and red muntjac $\left(\mathrm{U}^{2}=0.208, \mathrm{P}>0.05\right)$. However, the temporal appearance of leopard was not significantly different from gaur $\left(\mathrm{U}^{2}=0.314, \mathrm{P}>0.10\right)$ and Asiatic black bear $\left(\mathrm{U}^{2}=0.165\right.$, $\mathrm{P}>0.05)$. The appearance of tiger was not significantly different with banteng $\left(\mathrm{U}^{2}=0.124, \mathrm{P}>0.10\right)$, Malayan tapir $\left(\mathrm{U}^{2}=0.176, \mathrm{P}>0.05\right)$ and Asiatic black bear $\left(\mathrm{U}^{2}=0.033\right.$, $\mathrm{P}>0.05)$.

\section{Coefficient of temporal overlap}

From the study of temporal overlap of dhole, tiger, and leopard in the same site, it was found that the coefficient of temporal overlap $(\Delta)$ of dhole and tiger was 0.37 , while the coefficient of overlap $(\Delta)$ between dhole and leopard was 0.56 .

Placed in descending order based on overlap coefficient, dhole had temporal overlap with red muntjac, wild boar, sambar deer, banteng, gaur, Malayan porcupine, pig-tailed macaque, large Indian civet, Asiatic black bear, and red jungle fowl, which were the potential prey at the site.

Placed in descending order based on overlap coefficient, tiger had temporal overlap with large Indian civet, หambar deer, banteng, taur, Malayan porcupine, wild boar, red muntjac, red jungle fowl, pig-tailed macaque, and Asiatic black bear, which were the potential prey at the site. 
Table 7. The calculated temporal overlap coefficient $(\Delta)$ using Kernel density functions of dhole, tiger, leopard and their potential prey species activity sampled via camera trapping during November 2017 to March 2019, in Huai Kha Khaeng Wildlife Sanctuary, (1=identical activity), with approximate $95 \%$ bootstrap confidence intervals (BCI).

\begin{tabular}{|c|c|c|c|c|c|c|}
\hline \multirow{2}{*}{ Species } & \multicolumn{6}{|c|}{ Temporal overlap coefficient $(\Delta)$} \\
\hline & \multicolumn{2}{|c|}{ Dhole } & \multicolumn{2}{|c|}{ Tiger } & \multicolumn{2}{|c|}{ Leopard } \\
\hline Large felid & $\Delta$ & $95 \% \mathrm{BCI}$ & $\Delta$ & $95 \% \mathrm{BCI}$ & $\Delta$ & $95 \% \mathrm{BCI}$ \\
\hline Dhole & -- & -- & 0.37 & $0.28-0.46$ & 0.56 & $0.47-0.64$ \\
\hline Tiger & 0.37 & $0.28-0.46$ & -- & -- & 0.93 & $0.87-0.98$ \\
\hline Leopard & 0.56 & $0.47-0.64$ & 0.93 & $0.87-0.98$ & -- & - \\
\hline \multicolumn{7}{|l|}{ Potential prey } \\
\hline Red muntjac & 0.86 & $0.76-0.93$ & 0.48 & $0.43-0.55$ & 0.68 & $0.63-0.72$ \\
\hline Wild pig & 0.73 & $0.64-0.83$ & 0.68 & $0.61-0.74$ & 0.84 & $0.80-0.89$ \\
\hline Sambar deer & 0.44 & $0.35-0.53$ & 0.87 & $0.82-0.92$ & 0.91 & $0.87-0.94$ \\
\hline Banteng & 0.42 & $0.33-0.50$ & 0.87 & $0.82-0.92$ & 0.70 & $0.66-0.75$ \\
\hline Gaur & 0.33 & $0.24-0.43$ & 0.83 & $0.73-0.91$ & 0.76 & $0.69-0.84$ \\
\hline Malayan porcupine & 0.27 & $0.20-0.34$ & 0.72 & $0.66-0.78$ & 0.54 & $0.50-0.59$ \\
\hline Pig-tailed macaque & 0.15 & $0.05-0.27$ & 0.34 & $0.23-0.45$ & 0.51 & $0.39-0.62$ \\
\hline Large indian civet & 0.23 & $0.18-0.30$ & 0.88 & $0.82-0.93$ & 0.79 & $0.75-0.83$ \\
\hline Asiatic black bear & 0.76 & $0.55-0.92$ & 0.32 & $0.21-0.44$ & 0.70 & $0.54-0.85$ \\
\hline Red jungle fowl & 0.69 & $0.61-0.76$ & 0.39 & $0.33-0.45$ & 0.58 & $0.53-0.62$ \\
\hline
\end{tabular}

Placed in descending order based on overlap coefficient, leopard had temporal overlap with sambar deer, wild boar, large Indian civet, gaur, banteng, Asiatic black bear, red muntjac, red jungle fowl, Malayan porcupine, and pig-tailed macaque, which were the potential prey at the site as shown in Table 7.

\section{The overlap of prey}

The result of Pianka's prey overlap calculated from the coefficient of temporal overlap showed that the overlap index between dhole and tiger was 0.78 which was similar to that of dhole and leopard which was equal to 0.79 , as well as that of tiger and leopard which was 0.96 .

\section{Discussion}

The study results proved the hypothesis and revealed that the temporal overlaps between dhole, tiger, and leopard were insignificant although dhole, tiger, and leopard appeared in the same site and had greatly significant spatial overlap. It conformed to the study result of Ramesh et al. (2012) which revealed that there was no significant temporal overlap with tiger and leopard in the same site, while there was greatly significant spatial overlap between dhole, tiger, and leopard. The result of this study was different from the study of Ramesh et al. (2012) which reported that dhole did not have significant spatial overlap with tiger. However, this study found that dhole, tiger, and leopard had greatly significant spatial overlap. This was similar to the study results of Vinitpornsawan and Fuller (2020) which revealed that dhole, tiger, and leopard did not significantly have positive temporal overlap. It proved the avoidance process of large carnivores in the site which appeared at the same site but avoided each other in terms of time.

In this study, Pianka's prey overlap index of prey species from the analysis of dhole, and leopard scat was 0.79, and 0.98-0.99. Ramesh et al. (2012) and Charaspet et al. (2019) showed that the overlap of prey species of dhole and tiger was 0.78. Ramesh et al. (2012) and Charaspet et al. (2020) reported that the overlap index was 0.62-0.68. This was the reason which supported the temporal avoidance by which the positive spatial-temporal overlap of the three large carnivores was not significantly found.

The study result of spatial overlap between dhole and tiger $(0.43, \mathrm{P}<0.01)$ and dhole and leopard $(0.48, \mathrm{P}<0.01)$ was greatly and significantly positive, but the index was slightly less than that of dhole and leopard. The coefficient of overlap between dhole and tiger was lower in comparison to that between dhole and leopard. Temporal overlap studied from the coefficient of overlap between dhole and leopard was found to be higher than that of dhole and tiger. The result corresponded to spatial overlap. The spatial overlap index between tiger and leopard was significantly the highest $(0.56, \mathrm{P}<0.01)$. In comparison with the prey overlap index between leopard and tiger, the index was equal to 0.96. It showed that leopard were large carnivores which utterly overlapped with other large carnivores: tiger and dhole. This made the degree of time variability of leopard in a day higher than that of dhole and tiger. It was also the reason which made leopards mostly hunt between day and night times, while tiger hunted in the night time, and dhole hunted in the day time (see Table 6).

Charaspet et al. (2020) did not find banteng in the list of dhole prey in Huai Kha Khaeng Wildlife Sanctuary and Salak Phra Wildlife Sanctuary. However, banteng was discovered to be the second-most-hunted dhole prey from Bubalus bubalis (Nurvianto et al. 2016) in deciduous forest, in the east of Indonesia. As banteng was tiger's most favorite prey (Phetdee 2000), it might be the reason why it was not found on the list of dhole prey in Huai Kha Khaeng Wildlife Sanctuary. The study result showed that the temporal overlap between dhole and tiger was not found. It was confirmed by this study result revealed that the spatial- 
temporal appearance of banteng was negatively related to that of dhole.

Dhole had spatial-temporal overlap with 10 species of potential wild animal prey. In total, there were 28 potential prey species categorized in terms of simultaneous spatialtemporal overlaps, as well as individual overlap: either solely spatial or temporal overlap. In the meantime, tiger had spatial-temporal overlaps with 9 species of potential wild animal prey. In total, there were 28 potential prey species categorized in terms of simultaneous spatialtemporal overlaps, as well as individual spatial overlap. However, leopard did not have simultaneous spatialtemporal overlap with any other prey; it only had spatial overlap with 7 species of potential wild animal prey. Leopard also had temporal overlap with gaur only. The highest spatial-temporal overlap of dhole and potential prey signified the better capability of dhole in adjusting its hunting and consumption in comparison to tiger which needed prey with a more particular size. However, leopard did not have simultaneous spatial-temporal overlap with prey. However, the study on the prey overlap showed that leopard was the carnivore with the most vicious competition as it had Pianka's prey overlap index with tiger (0.96), and dhole (0.98-0.99) (Ramesh et al. 2012; Charaspet et al. 2019; 2020).

The coefficient of temporal overlap $(\Delta)$ of tiger and leopard was 0.93 which was considered high according to the overlap criteria of Lynam et al. (2013). The result revealed that dhole had a coefficient of temporal overlap with Red muntjac, its potential prey, in the highest level. It also overlapped with Asiatic black bear in the high level $(\Delta$ $=0.76)$. Asiatic black bear was also found in the list of dhole food (Kamler et al. 2020).

Placed in descending order, tiger had a coefficient of temporal overlap with large Indian civet, sambar deer, banteng, and gaur in the high level. It corresponded with the list of tiger food. Phetdee (2000) reported 18 categorized prey species of tiger. The species which were mostly found were banteng, sambar deer, red muntjac, gaur, wild boar, Malayan porcupine, Asiatic black bear, and Malayan pangolin respectively. In the meantime, leopard had the higest temporal overlap with sambar deer, wild boar, gaur, and large Indian civet respectively. This corresponded with Simcharoen (2008) who reported that there were 21 species of leopard prey which are mammals in Huai Kha Khaeng Wildlife Sanctuary. Sambar deer, Malayan porcupine, wild boar, red muntjac, banteng, and Phayre's langur were mostly found, respectively. It revealed that even though the main prey of large carnivores was repeated, the orders of frequency of the prey's appearance in the list of food were different based on physical size, and behaviors of large competitive carnivores, especially tiger and leopard. Pianka's prey overlap index of prey between tiger and leopard was 0.96 . The result of this calculation was higher than that of Mondal et al. (2012) and Lovari et al. (2015) which was equal to between $0.85-0.90$.

When particularly considering prey with a high coefficient of temporal overlap (>75) (Lynam et al. 2013), four prey species of tiger and leopard were equally found.
By considering tiger prey with high coefficiency of temporal overlap (>75), we found sambar deer, banteng, gaur, and large Indian civet. Leopard prey, by particularly considering the prey with high coefficiency of temporal overlap (>75), were sambar deer, wild boar, gaur, and large Indian civet. Dhole prey, by particularly considering the prey with high coefficiency of temporal overlap $(>75)$, were only red muntjac and Asiatic black bear. Dhole could hunt Asiatic black bear (Kamler et al. 2020), as well as tiger as shown in its list of food (Phetdee 2000). The result revealed that the number of dhole prey species that had spatial-temporal overlap was higher than those of tiger and leopard. Dhole was more generalist than tiger (Aryal et al. 2015).

The study result proved that apart from other wild animals, sambar deer, red muntjac, banteng, gaur, wild boar, large Indian civet, Asiatic black bear, Malayan porcupine, pig-tailed macaque, and red jungle fowl were potential prey of large carnivores depending on the chance of confrontation. Prey selection of large carnivores is related to the predator-prey fit size for the worthiness in hunting, as well as the abundance of the prey found.

Huai Kha Khaeng Wildlife Sanctuary is part of the fertile World's Natural Heritage with the least human disturbance. However, the outside-in wildfire in the site has constantly occurred, especially in the north and east ridge which is dry evergreen forest or rain forest. It is the important habitat of large carnivores. It presents a considerable problem that needs to be handled by focusing on fire control around tropical rain forest in the area. The site also comprises tropical deciduous forest which included deciduous forest and mixed forest. It is necessary to manage grass fields or increase open areas in order to increase the size of ungulate populations, especially sambar deer, banteng, red muntjac, gaur, and wild boar. They are important for conserving the population of large carnivores in the area. In addition, the development of neighboring areas of Huai Kha Khaeng Wildlife Sanctuary must not cause any effect, particularly the interaction between livestock and large ungulate wild animals. The spatial overlap between them presents potential danger as it risks livestock epidemics, especially hemorrhagic septicemia which was reported to be found in banteng which died in September 2019, foot-and-mouth disease which severely spread in 2014, and anthrax. If these pandemic diseases spread among wildlife animals, large carnivores in the site would also be affected. Furthermore, the patrols, especially in the east, by the officers to prevent any threats are essential in order to constantly conserve the population of the carnivores and prey in the area.

In conclusion, spatial overlap between dhole and leopard was higher in comparison to that of dhole and tiger because dhole and leopard had higher prey overlap. Large carnivores did not have temporal overlap in order to avoid each other. Spatial-temporal overlap of dhole and the potential preys showed higher numbers of prey in comparison to those of tiger and leopard. The result revealed that dhole had higher spatial overlap with leopard $(0.48, \mathrm{P}<0.01)$ in comparison to that of dhole and tiger (0.43, $\mathrm{P}<0.01)$. Tiger and leopard showed greatly 
significant spatial overlap $(0.56, \quad \mathrm{P}<0.01)$. Significant temporal overlaps between dhole and leopard and between tiger and leopard were found. It was found that dhole had negative temporal overlap with tiger $(-0.66, \mathrm{P}<0.01)$ which proved the hypothesis. The result of the study on spatial overlap conformed to Pianka's prey overlap index of this study which found that the index between dhole and leopard was 0.79 which was slightly higher than the index between dhole and tiger which was equal to 0.78 . However, Pianka's prey overlap index between tiger and leopard was 0.96. Therefore, leopard and tiger; dhole and leopard avoided each other and their temporal overlap was not found. It was discovered that the coefficient of temporal overlap between dhole and tiger was 0.37 , while that between dhole and leopard was 0.56 , and that between tiger and leopard was 0.93. It was found that dhole had spatialtemporal overlap with the highest number of prey species, followed by tiger. Leopard showed neither spatial nor temporal overlap with the potential wild animal prey. It also found 10 species of potential prey of large carnivores. They were sambar deer, red muntjac, gaur, banteng, wild boar, Malayan porcupine, large Indian civet, Asiatic black bear, and red jungle fowl. The large carnivores had different prey selection according to their specific characteristics: the abundance and the chance of confrontation with large carnivores, of each species. The important recommendations are the handling of outside-in wildfires, especially in dry evergreen forest, the development of grass, water, and saltlick resources to promote the prey population.

\section{ACKNOWLEDGEMENTS}

This study is financially supported by Earthwatch Institute, USA. The supportive fund for $\mathrm{Ph} . \mathrm{D}$. students of the Center for Advanced Studies in Tropical Natural Resources, Kasetsart University, Thailand. We would like to express my sincere gratitude to Thani Wongnak, former Head of Huai Kha Khaeng Wildlife Sanctuary, and Sompoj Duangchantrasiri, Head of Khao Nang Rum Wildlife Research Station for their support during field data collection. We also would likewise like to show our appreciation to the volunteers of Earthwatch for their help in camera trapping survey in the area. We would like to also express my appreciation to the Dean of the Faculty of Forestry, Kasetsart University for his support to this study.

\section{REFERENCES}

Agostinelli C, Lund U. 2017. R package "circular": Circular Statistics (version 0.4-7). CA: Department of Environmental Sciences, Informatics and Statistics, Ca' Foscari University, Venice, Italy. UL: Department of Statistics, California Polytechnic State University, San Luis Obispo, California, USA. https://r-forge.r6 project.org/projects/circular/

Aryal A, Panthi S, Barraclough RK, Bencini R, Adhikari B, Ji W, Raubenheimer D. 2015. Habitat selection and feeding ecology of Dhole (Cuon alpinus) in the Himalayas. J Mammal 96: 47-53.

Bhattarai BP, Kindlmann P. 2012. Interactions between Bengal tiger (Panthera tigris) and Leopard (Panthera pardus): Implications for their conservation. Biodivers Conserv 21:2075-2094. DOI: 10.1007/s10531-012-0298-y

Brodie J, Giordano AJ. 2012. Density of the vulnerable Sunda clouded leopard Neofelis diardi in a protected area in Sabah, Malaysian Borneo. Oryx 46: 427-430.

Bu H, Wang F, McShea WJ, Lu Z, Wang D, Li S. 2016. Spatial cooccurrence and activity patterns of mesocarnivores in the temperate forests of Southwest China. 11(10):e0164271. DOI: 10.1371/journal.pone.0164271

Charaspet K, Sukmasuang R, Kheowsree N, Songsasen N, Simchareon S, Duengkae P. 2019. Some ecological aspects of Dhole (Cuon alpinus) in the Huai Kha Khaeng Wildlife Sanctuary, Uthai Thani Province, Thailand. Folia Oecologica 46: 91-100.

Charaspet K, Sukmasuang R, Khoewsree N, Pla-ard M, Chanachai Y. 2020. Prey species and prey selection of dholes at three different sites in Thailand. Biodiversitas 21: 5248-5262.

Choo YR, Kudavidanage EP, Amarasinghe TR, Nimalrathna T, Chua MAH, Webb EL. 2020. Best practices for reporting individual identification using camera trap photographs. Glob Ecol Conserv 24: e01294. DOI: 10.1016/j.gecco.2020.e01294

Davis M, Faurby S, Svenning JS. 2018. Mammal diversity will take millions of years to recover from the current biodiversity crisis. PNAS 115 (44): 11262-11267. DOI: 10.1073/pnas.1804906115

Davis WT, Drymon JM, Powers SP. 2015. Pianka's niche overlap indices. PLOS ONE. Dataset. DOI: 10.1371/journal.pone.0144051.t004

Department of Land Development. 2016. Land Use Map of the Western Forest Complex. Ministry of Agriculture and Cooperatives. Bangkok.

Dou H, Yang H, Smith JLD, Feng L, Wang T, Ge J. 2019. Prey selection of Amur tigers in relation to the spatiotemporal overlap with prey across the Sino-Russian border. Wildlife Biol 1: 1-11.

Duangchantrasiri S, Umponjan M, Simcharoen S, Pattanavibool A, Chaiwattana S, Maneerat S, Kumar N, Jathanna D, Srivathsa A, Karanth K. 2016. Dynamics of a low-density tiger population in Southeast Asia in the context of improved law enforcement. Conserv Biol 30. 639-648. 10.1111/cobi.12655

Francis CM. 2019. Field Guide to the Mammals of South-East Asia. Bloomsbury Wildlife; 2nd edition New Holland, London, Cape Town, Sydney, Auckland

Frey W, Maroon EA, Pendergrass AG, Kay JE. 2017. Do Southern ocean cloud feedbacks matter for 21 st-century warming?. Geophys Res Lett 44: 12,447-12,456.

Hayward MW, Lyngdoh S, Habib B. 2014. Diet and prey preferences of Dholes (Cuon alpinus): Dietary competition within Asia's apex predator guild. J Zool 294(4): 255-266.

IBM Corp. Released. 2016. IBM SPSS Statistics for Windows, Version 24.0. Armonk, NY: IBM Corp. https://www01.ibm.com/support/docview.wss?uid=swg2 1476197

Jhala YV, Qureshi Q, Nayak AK. 2020. Status of Tigers, Copredators and Prey in India, National Tiger Conservation Authority, Government of India, New Delhi, and Wildlife Institute of India, Dehradun.

Kamler JF, Tatdokkham K, Rostro-García S, Bousa A, Caragiulo A, Crouthers R, Pay VIC, Pin C, Prum S, Vongkhamheng C, Johnson A, Macdonald DW. 2020. Diet and prey selection of dholes in evergreen and deciduous forests of southeast Asia. J Wildl Manage 84(7): 13961405 .

Karanth KU, Srivathsa A, Vasudev D, Puri M, Parameshwaran R, Kumar NS. 2017. Spatio-temporal interactions facilitate large carnivore sympatry across a resource gradient. Proc $\mathrm{R}$ Soc Lond DOI: 10.1098/rspb.2016.1860

Kerley LL, Mukhacheva AS, Matyukhina DS, Salmanova E, Salkina GP, Miquelle DG. 2015. A comparison of food habits and prey preference of Amur tiger (Panthera tigris altaica) at three sites in the Russian Far East. Integr Zool 10(4): 354-364. DOI: 10.1111/17494877.12135 .

Khoewsree N, Charaspet K, Sukmasuang R, Songsasen N, Pla-ard M, Thongbantum J, Kongchaloem W, Srinopawan K. 2020. Abundance, prey, and activity period of Dholes (Cuon alpinus) in Khao Yai National Park, Thailand. Biodiversitas 21: 345-354.

Kovach W. 2011. Oriana - Circular Statistics for Windows, ver. 4.02. Pentraeth: Kovach Computing Services.

Kumaraguru A, Saravanamuthu R, Brinda K, Asokan S. 2011. Prey preference of large carnivores in Anamalai Tiger Reserve, India. Eur J Wildl Res 57: 627-637.

Lovari S, Pokheral CP, Jnawali SR, Fusani L, Ferretti F. 2015. Coexistence of the tiger and the common leopard in a prey-rich area: The role of prey partitioning. J Zool 295(2): 122-131. 
Lynam AJ, Jenks KE, Tantipisanuh N, Chutipong W, Ngoprasert D, Gale GA, Steinmetz R, Sukmasuang R, Bhumpakphan N, Grassman LI. 2013. Terrestrial activity patterns of wild cats from camera-trapping. Raffles Bull Zool 61(1): 407-415

Meredith M, Ridout M. 2020. Package 'Overlap'. R package version 4.0.2. 1-20. http://CRAN.R-project.org/package=overlap.

Mondal K, Gupta S, Bhattacharjee S, Qureshi Q, Sankar K. 2012. Prey selection, food habits and dietary overlap between leopard Panthera pardus (Mammalia: Carnivora) and re-introduced tiger Panthera tigris (Mammalia: Carnivora) in a semi-arid forest of Sariska Tiger Reserve, Western India. Ital J Zool (Modena). 79(4): 607-616. http://doi:10.1080/11250003.2012.687402

Nurvianto S, Eprilurahman R, Imron MA, Herzog S. 2016. Feeding habits of pack living dhole (Cuon alpinus) in a dry deciduous forest of east Java, Indonesia. Taprobanica 8(1): 10-20.

Oliver R. Wearn OR, Glover-Kapfer P. 2017. Conservation Technology: Camera-Trapping for Conservation: a Guide to Best-practices. WWF Conservation Technology Series 1(1). WWF-UK, Woking, United Kingdom. DOI: 10.13140/RG.2.2.23409.17767

Pereira P, da Silva AA, Alves J, Matos M, Fonseca C. 2012. Coexistence of carnivores in a heterogeneous landscape: habitat selection and ecological niches. Ecol Res 27(4) DOI: 10.1007/s11284-012-0949-1

Phetdee. 2000. Food Habits of the Tiger (Pantera tigris Linnaeus) in Huai Kha Khaeng Wildlife Sanctuary by Fecal Analysis. [Dissertation]. Kasetsart University, Thailand. [Thai]

Qi J, Holyoak M, Ning Y, Jiang G. 2020. Ecological thresholds and large carnivores conservation: Implications for the Amur tiger and leopard in China Glob Ecol Conserv 21: e00837. DOI: 10.1016/j.gecco.2019.e00837

Rafiq K, Hayward MW, Wilson AM, Meloro C, Jordan NR. Wich SA McNutt JW, Golabek KA. 2020. Spatial and temporal overlaps between leopards (Panthera pardus) and their competitors in the African large predator guild. J Zool 311: 246-259.

Ramesh. 2010. Prey Selection and Food Habits of Large Carnivores: Tiger Panthera tigris, Leopard Panthera pardus and Dhole Cuon alpinus in Mudumalai Tiger Reserve, Tamil Nadu. [Dissertation]. Saurashtra University, India

Ramesh T, Kalle R, Sankar K, Qureshi Q. 2012. Dietary partitioning in sympatric large carnivores in a tropical forest of Western Ghats, India. Mammal Study 37: 313-321.

Rasphone A, Kamler JF, Macdonald DW. 2020. Temporal partitioning by felids, dholes and their potential prey in northern Laos. Mammal Res 65: 679-689. DOI: /10.1007/s13364-020-00524-9.

Rich M, Thompson C, Prange S, Popescu VD. 2018. Relative importance of habitat characteristics and interspecific relations in determining terrestrial carnivore occurrence. Front Ecol Evol DOI: 10.3389/fevo.2018.00078

Rovero F, Zimmermann F, Berzi D, Meek P. 2013. "Which camera trap type and how many do I need?" A review of camera features and study designs for a range of wildlife research applications Hystrix DOI: $10.4404 /$ hystrix-24.2-8789

Saisamorn A, Duengkae P, Pattanavibool A, Duangchantrasiri S, Soen A, Smith JLD. 2019. Spatial and temporal analysis of Leopards (Panthera pardus), their prey and Tigers (Panthera tigris) in Huai Kha Khaeng Wildlife Sanctuary, Thailand. Folia Oecologica 46(2):73-82. DOI: 10.2478/foecol-2019-0010.

Selvan KM, Veeraswami GG, Hussain SA. 2013. Dietary preference of the Asiatic wild dog (Cuon alpinus). Mamm Biol 78: 486-489.

Simcharoen. 2008. Ecology of the Leopard (Panthera Pardus Linn.) in Huai Kha Khaeng Wildlife Sanctuary. [Dissertation]. Kasetsart University, Thailand. [Thai]

Simcharoen S, Duangchantrasiri S. 2008. Monitoring of the leopard population at Khao Nang Rum in Huai Kha Khaeng Wildlife Sanctuary. Thai J For 27: 68-80.

Steinmetz R, Seuaturien N, Chutipong W. 2013. Tigers, leopards, and dholes in a half-empty forest: Assessing species interactions in a guild of threatened carnivores. Biol Conserv 163: 79-89.

Vinitpornsawan S. Fuller TK. 2020. Spatio-temporal correlations of large predators and their prey in western Thailand. Raffles Bull Zool 68: 118-131.

Vinitpornsawan. 2013. Population and Spatial Ecology of Tigers and Leopards Relative to Prey Availability and Human Activity in Thung Yai Naresuan (East) Wildlife Sanctuary, Thailand. [Dissertation]. University of Massachusetts, USA.

Western Forest Complex. 2004. GIS Database and its Applications for Ecosystem Management. The Western Forest Complex Ecosystem Management Project, Department of National Park, Wildlife, and Plant Conservation, Bangkok, Thailand.

Węglarczyk S. 2017. Kernel density estimation and its application ITM Web of Conferences 23: 00037 (2018). DOI: 10.1051/itmconf/20182300037

Zaragozí B, Belda A, Giménez P, Navarro JT, Bonet A, et al. 2015. Advances in integration with GIS. Ecol Inform 30: 6-11.

Zhang J. 2016. Package 'spaa'. www.cran.rproject.org/web/packages/spaa/spaa.pdf.

Zhou Z, Wang C, Luo Y. 2020. Meta-analysis of the impacts of global change factors on soil microbial diversity and functionality. Nat. Commun. 11: 3072. www.nature.com/naturecommunications. 